\title{
The impact of muscle function, muscle mass and sarcopenia on independent ageing in very old Swedish men
}

\author{
Kristin Franzon ${ }^{1 *}$ D, Björn Zethelius ${ }^{1}$, Tommy Cederholm² and Lena Kilander ${ }^{1}$
}

\begin{abstract}
Background: Preserved functions of daily life and cognition are cornerstones of independent aging, which is crucial for maintaining a high quality of life. The aim of this study was to examine the impact of sarcopenia, and its underlying components, on independent ageing in a cohort study of very old men.

Methods: The presence of sarcopenia and independent ageing at a mean age of 87 was investigated in 287 men from the Uppsala Longitudinal Study of Adult Men. Five years later 127 men were re-evaluated for independent ageing. Sarcopenia was defined by two different definitions from the European Working Group on Sarcopenia in Older People. In the first definition sarcopenia was defined as skeletal muscle index $<7.26 \mathrm{~kg} / \mathrm{m}^{2}$ and either gait speed $\leq 0.8$ $\mathrm{m} / \mathrm{s}$ or hand grip strength $<30 \mathrm{~kg}$. In the later up-dated definition, $\mathrm{HGS}<27 \mathrm{~kg}$ and/or chair stand test $>15 \mathrm{~s}$ defines probable sarcopenia, which is confirmed by $\mathrm{SMl}<7.0 \mathrm{~kg} / \mathrm{m}^{2}$. Independent ageing was defined as a Mini-Mental State Examination score of $\geq 25$ points, absence of diagnosed dementia, community-dwelling, independency in personal care and ability to walk outdoors alone.
\end{abstract}

Results: Sarcopenia at baseline was observed in 21\% (60/287) and 20\% (58/287), respectively, due to definition. The prevalence of independent ageing was $83 \%$ (239/288) at baseline and 69\% (87/127) five years later. None of the sarcopenia diagnoses were associated with independent ageing. In contrast, gait speed was both in cross-sectional (odds ratio (OR) per one standard deviation increase 2.15, 95\% confidence interval (Cl) 1.47-3.15), and in longitudinal multivariate analyses (OR 1.84, 95\% Cl 1.19-2.82). In the cross-sectional analysis also higher hand grip strength was associated with independent ageing (OR 1.58,95\% Cl 1.12-2.22), while a slower chair stand test was inversely associated (OR 0.61, 95\% Cl 0.43-0.86). Muscle mass; i.e. skeletal muscle index, was not associated with independent ageing.

Conclusions: For very old men, especially a higher gait speed, but also a higher hand grip strength and a faster chair stand test, were associated with independent ageing, while skeletal muscle index alone, and the composite sarcopenia phenotype measured with two different definitions, were not.

Keywords: Sarcopenia, EWGSOP1, EWGSOP2, Muscle mass, Muscle function, Gait speed, Hand grip strength, Chair stand test, Independent ageing

\footnotetext{
*Correspondence: kristin.franzon@pubcare.uu.se

'Department of Public Health and Caring Sciences/Geriatrics, Uppsala

University, Box 564, 75122 Uppsala, Sweden

Full list of author information is available at the end of the article
}

(c) The Author(s). 2019 Open Access This article is distributed under the terms of the Creative Commons Attribution 4.0 International License (http://creativecommons.org/licenses/by/4.0/), which permits unrestricted use, distribution, and reproduction in any medium, provided you give appropriate credit to the original author(s) and the source, provide a link to the Creative Commons license, and indicate if changes were made. The Creative Commons Public Domain Dedication waiver (http://creativecommons.org/publicdomain/zero/1.0/) applies to the data made available in this article, unless otherwise stated. 


\section{Background}

Very old individuals value functional independence higher than absence of morbidity [1]. This health valuation is in line with our concept of independent ageing $[2,3]$, defined as preserved ability to perform personal activities of daily living (ADL), walking outdoors and cognitive function. Thus, independent ageing requires preserved function of the neuromuscular system. With this in mind, sarcopenia can be one reason for not achieving independent ageing. Sarcopenia was initially defined as low muscle mass only [4], but now there is an agreement that low muscle mass must be combined with low muscle function to define sarcopenia [5-8]. However, how to measure muscle mass or function is still an open question [5-8]. In 2010, the European Working Group on Sarcopenia in Older People (EWGSOP) defined sarcopenia as low appendicular skeletal muscle mass and low gait speed (GS) and/or hand grip strength (HGS) [5]. Recently this definition was up-dated, when low muscle strength was further emphasized as a key characteristic of sarcopenia [8]. In the EWGSOP2 definition, low muscle strength, measured by HGS and/or chair stand test (CST), is defined as probable sarcopenia. Sarcopenia is then confirmed by low appendicular skeletal muscle mass, while tests of physical performance (e.g. gait speed (GS)) add information of the severity of the sarcopenia. Studies using the updated sarcopenia definition are so far scarce $[9,10]$.

In two meta-analyses, sarcopenia was associated with functional decline and cognitive impairment, respectively $[11,12]$. However, studies on individuals $\geq 80$ years are rare. Two studies have investigated the association between sarcopenia and cognitive impairment [13, 14], but to our knowledge there has been no previous study on this age group concerning the association between sarcopenia and ADL function or outdoor walking. Furthermore, studies in this field with functional and cognitive impairment as a combined outcome are rare for all ages [15-18].

The aim of this study was to investigate the cross-sectional and longitudinal associations between sarcopenia defined by the two EWGSOP definitions and independent ageing, and among their respective components. A cohort of Swedish men with a mean age of 87 at baseline and with follow-up five years later was used.

\section{Methods}

\section{Study population}

The Uppsala Longitudinal Study of Adult Men (ULSAM) started in 1970 [19]. All men born in the period 1920-24 and living in Uppsala were invited to the study, and $82 \%(n=2322)$ participated in the first investigation at the age of 50 . The baseline for the present study was the investigation conducted in 2008-09 at a mean age of $87(n=354)$ (Fig. 1). Of these participants, it was possible to define 287 men with regard to both independent ageing and sarcopenia. No exclusion criteria were applied. Forty-nine participants did not fulfil the criteria for independent ageing at baseline and 87 men had died before follow-up. Thus, 105 participants were re-examined in 2013-15 at a mean age of 92. Another 46 men declined to participate but it was possible to re-evaluate 22 of these concerning dementia, living conditions and ADL after a review of their medical records.

The study was approved by the Regional Ethical Review Board at Uppsala University, and all subjects provided written informed consent.

\section{Sarcopenia and covariates at baseline}

Body composition, including total fat mass, was measured by dual energy X-ray absorptiometry (DXA) using a DPX Prodigy, Lunar corp., Madison, WI, USA. Skeletal muscle index (SMI) was calculated by dividing the sum of the lean mass in the arms and legs by height squared $\left(\mathrm{kg} / \mathrm{m}^{2}\right)$. GS was assessed in 284 men using a $10-\mathrm{m}$ course. Participants were instructed to walk at a comfortable speed, and GS was derived from the middle $6 \mathrm{~m}$. If needed, an assistive device was allowed. HGS was measured in 285 men using a Baseline ${ }^{\odot}$ hydraulic hand dynamometer. Both hands were measured three times and the highest value was used. CST was assessed in 244 men. The participant was asked to rise five times from a seated position with arms folded across the chest, and the time needed was measured. Sarcopenia was defined using both the old (2010) and the new (2018) definitions proposed by the EWGSOP $[5,8]$. According to EWGSOP1, sarcopenia was defined as SMI $<7.26 \mathrm{~kg} / \mathrm{m}^{2}$ and GS $\leq 0.8 \mathrm{~m} / \mathrm{s}$ and/or HGS < $30 \mathrm{~kg}$ [5]. In the EWGSOP2 definition, probable sarcopenia was defined by low muscle strength, i.e. HGS $<27 \mathrm{~kg}$ and/or CST $>15 \mathrm{~s}$ [8]. Low muscle strength together with $\mathrm{SMI}<7.0 \mathrm{~kg} / \mathrm{m}^{2}$ confirmed the sarcopenia diagnosis and severe sarcopenia was present if $\mathrm{GS} \leq 0.8 \mathrm{~m} / \mathrm{s}$.

Educational level was classified as low $[<8$ years], medium [ $8-13$ years], or high [ $>13$ years]). At baseline a valid questionnaire $[20,21]$ was used to obtain information on leisure-time physical activity: sedentary (mainly reading or watching television), moderate (walking outdoors or cycling regularly), regular (sports or strenuous gardening $\geq 3 \mathrm{~h}$ per week) and athletic (regular strenuous physical activity). Participants were categorised as living with someone (spouse/cohabitant, other relatives) or not. Participants who smoked at baseline and/or at the fifth investigation cycle at mean age 82 were categorised as smokers. The National Patient Registry provided information on in-patient care before baseline, and this information was used to calculate Charlson's Comorbidity Index $[22,23]$. Weight and height were measured by a 


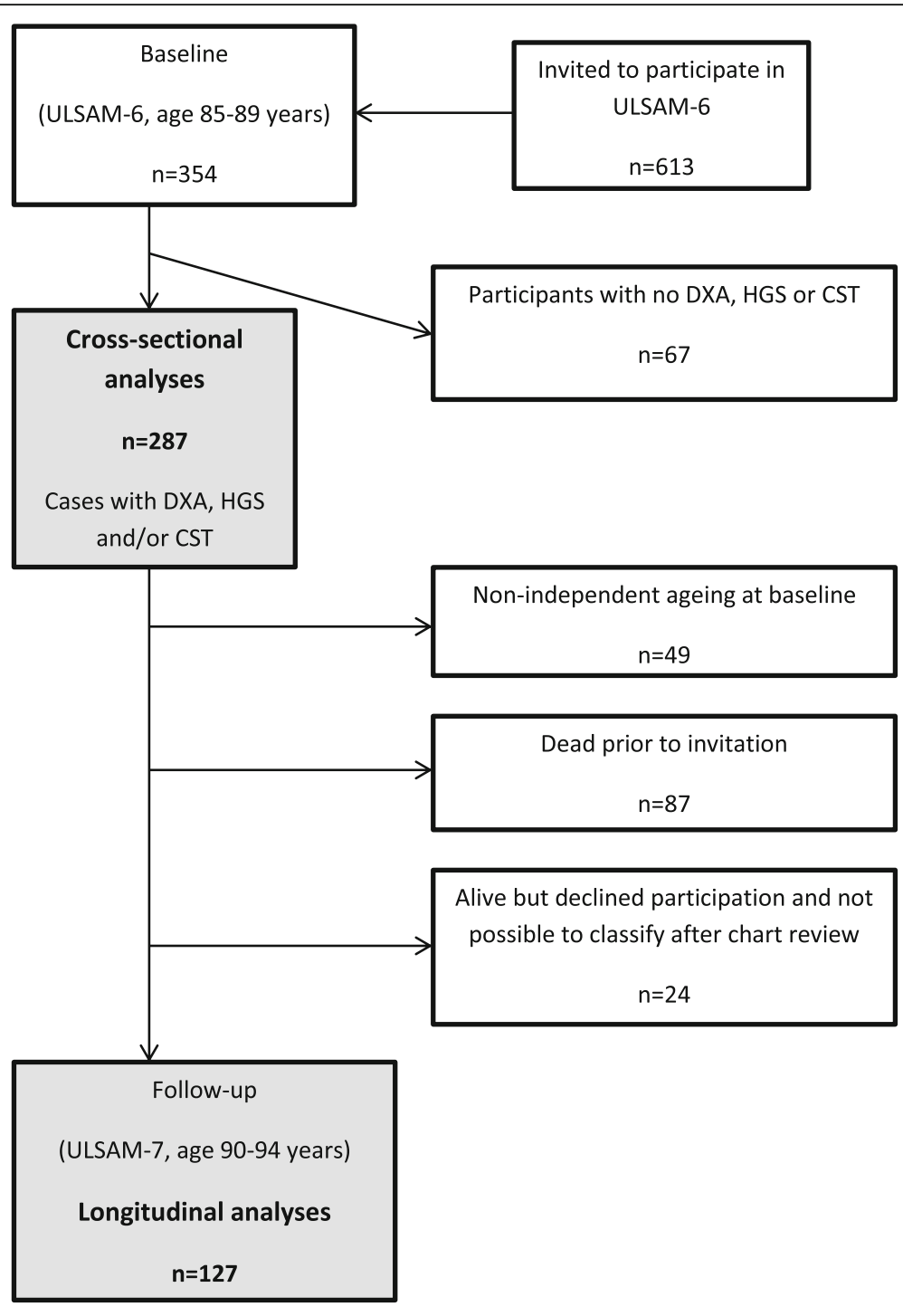

ULSAM- 6 = sixth investigation cycle of the Uppsala Longitudinal Study of Adult Men (ULSAM),

ULSAM-7 = seventh investigation cycle of the ULSAM. DXA = dual energy X-ray absorptiometry, HGS =

hand grip strength, CST $=$ chair stand test.

Fig. 1 Flow chart of study participants. ULSAM- $6=$ sixth investigation cycle of the Uppsala Longitudinal Study of Adult Men (ULSAM), ULSAM7 = seventh investigation cycle of the ULSAM. DXA = dual energy X-ray absorptiometry, HGS = hand grip strength, CST = chair stand test

research nurse, and body mass index (BMI) was calculated $\left(\mathrm{kg} / \mathrm{m}^{2}\right)$.

\section{Independent ageing}

Independent ageing, at baseline and follow-up, was defined as Mini-Mental State Examination [24] (MMSE) $\geq 25$ points, absence of diagnosed dementia, community-dwelling, independence in personal ADL and ability to walk outdoors alone. An experienced research nurse administered the MMSE to 287 men at baseline and 95 men at follow-up. Two geriatricians independently determined dementia status according to best practice and pre- specified criteria [25-29] using all data available in the medical records from Uppsala University Hospital, primary care and nursing homes in Uppsala County until April 1, 2009 and January 1, 2015, respectively. A questionnaire including questions on living conditions, ADLs (bathing, dressing, toileting) and ability to walk outdoors (assistive device allowed) were answered by 211 men at baseline and 104 men at follow-up. The medical records were reviewed for consistency with the self-reported information, and these provided supplemental information on participants not answering the questionnaire. Data on living conditions were provided by the Swedish Population 
Register. The medical records of non-participants at follow-up were also reviewed and it was possible to classify another 22 men, except regarding performance on the MMSE, and include them in the longitudinal analysis (Fig. 1).

\section{Statistical methods}

Continuous variables are presented as means and standard deviations (SD) and categorical variables as the number of individuals and percentages. We used logistic regression to calculate the odds ratios (ORs) and $95 \%$ confidence intervals (CIs) of the association of the exposure variables with independent ageing and its components.

SMI, GS, HGS and CST are presented as continuous variables standardised so that the estimates indicate the OR per SD increase in the variable. The covariates included in the multivariable model were age, smoking status, Charlson comorbidity index and total fat mass. The statistical software package JMP 13 for PC (SAS Corporation, Cary, NC, USA) was used for all analyses.

\section{Results}

The baseline characteristics are presented in Table 1. The prevalence of sarcopenia was $21 \%$ according to the original EWGSOP definition. With the updated EWGSOP2 definition, the prevalence of probable sarcopenia was $73 \%$, confirmed sarcopenia $20 \%$ and severe sarcopenia $2 \%$. Six percent displayed GS $\leq 0.8 \mathrm{~m} / \mathrm{s}$ and $61 \%$ performed the chair stand test in $>15 \mathrm{~s}$. Close to half $(46 \%)$ had HGS below $30 \mathrm{~kg}$ and $28 \%$ below $27 \mathrm{~kg}$. The prevalence of independent ageing was $83 \%$ at baseline, and $69 \%$ five years later (Table 2). Those who were re-examined $(n=127)$ had a higher prevalence of never smoking and less morbidity than the total population ( $n$ $=287$ ). Table 2 presents the prevalence of the different components of independent ageing. At baseline, 99\% of the participants were community-dwelling and $95 \%$ were free from dementia.

Table 3 shows the adjusted cross-sectional associations between sarcopenia and independent ageing. Severe sarcopenia was associated with loss of independent ageing and needing assistance with outdoor walking. No other sarcopenia category was associated with independent ageing or its separate components. Higher GS and HGS were associated with independent ageing and no assistance with outdoor walking. Higher GS was also associated with MMSE $\geq 25 \mathrm{p}$ and independency in personal care. Further, slower CST was inversely associated with independent ageing. There were no associations between SMI and independent ageing or the single components.

Table 4 presents the adjusted associations between sarcopenia at baseline and independent ageing five years later. Higher GS was associated with maintained independent ageing and no need of assistance with personal care, while higher HGS was associated with still being community-dwelling. There were no associations between the different sarcopenia definitions, SMI or CST and subsequent independent ageing or its individual components.

\section{Discussion}

The major finding of this study was that higher GS and HGS and less time to perform CST were associated cross-sectionally with independent ageing in very old men. Higher GS at baseline was also associated with independent ageing five years later. Further, severe sarcopenia, only present in $2 \%$, was associated with non-independent ageing in the cross-sectional analyses. However, there was no association between SMI or the other sarcopenia categories, as defined according to the EWGSOP1 and 2 criteria [5, 8], and independent ageing.

Regarding functional variables, both GS and HGS are well-established markers of biological ageing so the findings are not surprising [30-34]. However, studies of the oldest old with outcomes similar to ours are scarce [16, 18]. In the Honolulu Heart Program, high GS and HGS at mean age 76 was not associated with healthy ageing at age 85 [18]. Healthy ageing was defined as being free from major diseases, no physical limitation and with normal cognitive test performance [18]. However, in the cross-sectional Helsinki Businessmen Study, higher GS was correlated with active and healthy ageing in octogenarian men [16]. In contrast to the present study, the criteria for active and healthy ageing were self-reported and included "feeling happy", absence of major diseases, functional or cognitive impairment [16]. Lower HGS was also correlated with the combination of physical and cognitive impairment in a cross-sectional study in participants with a mean age of 68 years [15]. To the best of our knowledge, there are, so far, no studies of the association between CST and combined cognitive and physical function.

In the ULSAM, higher GS was correlated with well-preserved cognition at baseline, which is in line with other studies on very old subjects [13, 35-37], and confirmed by a meta-analysis [33]. One explanation of this relationship can be white matter lesions or neurodegeneration in brain areas involved in both gait and cognitive functions [38]. However, we could not confirm the results from other longitudinal reports showing an association between high GS and lower risk of cognitive decline $[34,35,39]$. One reason for this may be loss to follow-up, i.e. men with incident cognitive impairment declined to participate in the MMSE at follow-up. HGS was not associated with cognition in the present study and previous results are inconsistent. Two different cross-sectional studies on old women showed opposite 
Table 1 Baseline characteristics of the populations used for the cross-sectional and longitudinal analyses, respectively

\begin{tabular}{|c|c|c|}
\hline & $\begin{array}{l}\text { Total population in cross- } \\
\text { sectional analyses } n=287\end{array}$ & $\begin{array}{l}\text { Participants who were followed up } \\
\text { in longitudinal analyses } n=127\end{array}$ \\
\hline Age (years), mean $\pm S D$ & $86.6 \pm 1.0$ & $86.5 \pm 1.0$ \\
\hline \multicolumn{3}{|l|}{ Educational level, n (\%) } \\
\hline Low & $140(49)$ & $56(44)$ \\
\hline Medium & $88(31)$ & $44(35)$ \\
\hline High & $59(21)$ & $27(21)$ \\
\hline \multicolumn{3}{|l|}{ Physical activity, n (\%) } \\
\hline Sedentary & $49(24)$ & $13(14)$ \\
\hline Moderate & $82(40)$ & $42(47)$ \\
\hline Regular & $69(33)$ & $30(33)$ \\
\hline Athletic & $6(3)$ & $5(6)$ \\
\hline Living with someone, n (\%) & $137(65)$ & $67(73)$ \\
\hline \multicolumn{3}{|l|}{ Smoking status, n (\%) } \\
\hline Smoker & $16(6)$ & $4(3)$ \\
\hline Former smoking & $155(54)$ & $64(50)$ \\
\hline Never smoking & $116(40)$ & $59(46)$ \\
\hline \multicolumn{3}{|l|}{ Charlson Comorbidity Index, n (\%) } \\
\hline 0 & $111(39)$ & $60(47)$ \\
\hline 1 & $104(36)$ & $51(40)$ \\
\hline$\geq 2$ & $72(25)$ & $16(13)$ \\
\hline Body mass index, $\mathrm{kg} / \mathrm{m}^{2}$, mean $\pm \mathrm{SD}$ & $25.6 \pm 3.3$ & $25.8 \pm 3.0$ \\
\hline Total fat mass, kg, mean \pm SD & $22.2 \pm 7.5$ & $22.8 \pm 7.4$ \\
\hline \multicolumn{3}{|l|}{ EWGSOP1 } \\
\hline Sarcopenia, n (\%) & $60(21)$ & $25(20)$ \\
\hline \multicolumn{3}{|l|}{ EWGSOP2 } \\
\hline Probable sarcopenia, n (\%) & $209(73)$ & $81(64)$ \\
\hline Confirmed sarcopenia, n (\%) & $58(20)$ & $24(19)$ \\
\hline Severe sarcopenia, n (\%) & $5(2)$ & $1(0.8)$ \\
\hline Skeletal muscle index, $\mathrm{kg} / \mathrm{m}^{2}$, mean $\pm \mathrm{SD}$ & $7.5 \pm 0.8$ & $7.5 \pm 0.7$ \\
\hline$<7.0 \mathrm{~kg} / \mathrm{m}^{2}$ & $72(25)$ & $34(27)$ \\
\hline$<7.26 \mathrm{~kg} / \mathrm{m}^{2}$ & $109(38)$ & $49(39)$ \\
\hline Gait speed, $\mathrm{m} / \mathrm{s}$, mean $\pm \mathrm{SD}$ & $1.4 \pm 0.3$ & $1.5 \pm 0.3$ \\
\hline$\leq 0.8 \mathrm{~m} / \mathrm{s}$ & $16(6)$ & $2(2)$ \\
\hline Hand grip strength, $\mathrm{kg}$, mean $\pm S D$ & $30.2 \pm 6.5$ & $31.2 \pm 6.1$ \\
\hline$<27 \mathrm{~kg}$ & $79(28)$ & $32(25)$ \\
\hline$<30 \mathrm{~kg}$ & $132(46)$ & $53(42)$ \\
\hline Chair stand test, $\mathrm{s}$, mean $\pm \mathrm{SD}$ & $17.9 \pm 7.1$ & $16.4 \pm 6.0$ \\
\hline$>15 s$ & $148(61)$ & $54(48)$ \\
\hline
\end{tabular}

SD standard deviation, EWGSOP European Working Group on Sarcopenia in Older People

results $[13,40]$. In the Leiden 85 -plus Study, low HGS was cross-sectionally correlated with a lower MMSE and also predicted an accelerated decline in MMSE-score four years later [41]. Furthermore, a review of longitudinal studies showed an association between low HGS and decline in cognition [31]. In a US study in nonagenarians slower CST was cross-sectionally associated with dementia [37], while no association was seen between slower CST at baseline and dementia 2.6 years later [42]. Walking and chair-rising are complex activities that depend on more than just strength. Thus, GS and CST might be more sensitive than HGS to cognitive 
Table 2 Prevalence of Independent ageing and its indicators at baseline and 5 years later

\begin{tabular}{lll}
\hline & $\begin{array}{l}\text { Total population at mean age 87 years } \\
\text { Cross-sectional analyses } \\
\text { No of cases/no. of subjects (\%) }\end{array}$ & $\begin{array}{l}\text { Participants who were followed up at mean age 92 years } \\
\text { Longitudinal analyses }\end{array}$ \\
\hline Independent aging & $239 / 287(83)$ & $87 / 127(69)$ \\
Mini-Mental State Examination score $\geq 25 p$ & $252 / 287(88)$ & $85 / 95(89)$ \\
No diagnosis of dementia & $272 / 287(95)$ & $112 / 127(88)$ \\
Community-dwelling & $284 / 287(99)$ & $112 / 127(88)$ \\
No assistance with personal care ${ }^{a}$ & $274 / 286(96)$ & $107 / 125(86)$ \\
No assistance with outdoor walking & $274 / 285(96)$ & $106 / 119(89)$ \\
\hline
\end{tabular}

${ }^{\mathrm{a}}$ Independent in bathing, dressing and toileting

function and also to skeletomuscular disorders, such as arthritis. Further studies are needed on CST, which is a functional measure that is less investigated than GS and HGS. In the present study, higher GS was associated with independency in personal care five years later, which is in line with previous reports [32, 43-45]. Other longitudinal reports, but not our study, have also shown an association between lower GS and immobility [32, 44]. High HGS was cross-sectionally associated with independency in outdoor walking in ULSAM, which is in line with a previous review [31]. Although other reports have shown a relationship between low HGS and subsequent dependence in personal $\mathrm{ADL}$ the associations were not significant in our study [31, 41, 43]. In an American study, low GS and HGS were associated with institutionalisation six years later, independently of chronic conditions [43]. This is in contrast to our current findings in the ULSAM cohort, which show associations between low HGS, but not low GS, and institutionalisation five years later, also independently of comorbidity. One explanation of the different findings may be the high mean GS in the present population. CST was not associated with any of the single components of independent ageing. No other studies of the association between CST and institutionalization or disability in ADL and mobility in the oldest old have been found.

Regarding muscle mass, similar to our study the cross-sectional study by Tolea et al. found no association between low muscle mass measured by bio-electrical impedance analysis (BIA) and the combination of physical and cognitive impairment [15]. The MEDIS study reported that higher SMI was cross-sectionally associated with successful ageing [17]. However, that study included both genders, with an age range of 65-100 years. Furthermore, SMI was equation-based and the successful ageing index added together 10 components including education, BMI, physical activity and social

Table 3 Cross-sectional associations between sarcopenia and independent ageing at baseline, and between their respective components

\begin{tabular}{|c|c|c|c|c|c|c|}
\hline & $\begin{array}{l}\text { Independent } \\
\text { aging }\end{array}$ & MMSE $\geq 25 p$ & No dementia & Community-dwelling & $\begin{array}{l}\text { No assistance with } \\
\text { personal care }\end{array}$ & $\begin{array}{l}\text { No assistance with } \\
\text { outdoor walking }\end{array}$ \\
\hline & $n=239$ & $n=252$ & $n=272$ & $n=284$ & $n=274$ & $n=274$ \\
\hline & \multicolumn{6}{|c|}{ Odds ratio (95\% Confidence interval) } \\
\hline \multicolumn{7}{|l|}{ EWGSOP1 } \\
\hline Sarcopenia & $1.08(0.47-2.46)$ & $1.63(0.58-4.55)$ & $\mathrm{n} / \mathrm{a}$ & $\mathrm{n} / \mathrm{a}$ & $2.16(0.25-18.9)$ & $0.37(0.080-1.68)$ \\
\hline \multicolumn{7}{|l|}{ EWGSOP2 } \\
\hline Probable sarcopenia & $0.54(0.23-1.24)$ & $0.65(0.26-1.60)$ & $1.49(0.41-5.35)$ & $\mathrm{n} / \mathrm{a}$ & $1.08(0.20-5.79)$ & $1.23(0.22-6.88)$ \\
\hline Confirmed sarcopenia & $0.69(0.31-1.50)$ & $0.75(0.31-1.82)$ & $\mathrm{n} / \mathrm{a}$ & $\mathrm{n} / \mathrm{a}$ & $1.65(0.19-14.6)$ & $0.54(0.099-2.98)$ \\
\hline Severe sarcopenia & $0.087(0.013-0.59)$ & $0.47(0.048-4.50)$ & $\mathrm{n} / \mathrm{a}$ & $\mathrm{n} / \mathrm{a}$ & $0.080(0.0062-1.03)$ & $0.015(0.0013-0.17)$ \\
\hline Skeletal muscle index ${ }^{a}, \mathrm{~kg} / \mathrm{m}^{2}$ & $1.05(0.75-1.46)$ & $0.97(0.66-1.41)$ & $1.11(0.64-1.92)$ & $0.48(0.13-1.73)$ & $0.87(0.44-1.74)$ & $0.97(0.48-1.94)$ \\
\hline Gait speed $^{\mathrm{a}}, \mathrm{m} / \mathrm{s}$ & $2.15(1.47-3.15)$ & $1.70(1.14-2.56)$ & $1.54(0.82-2.89)$ & $1.02(0.23-4.52)$ & $2.34(1.10-5.02)$ & $3.75(1.59-8.85)$ \\
\hline Hand grip strength ${ }^{a}, \mathrm{~kg}$ & $1.58(1.12-2.22)$ & $1.24(0.80-1.80)$ & $1.45(0.83-2.56)$ & $0.60(0.17-2.14)$ & $1.65(0.85-3.18)$ & $2.35(1.16-4.77)$ \\
\hline Chair stand test $^{a}, \mathrm{~s}$ & $0.61(0.43-0.86)$ & $0.85(0.57-1.26)$ & $1.06(0.49-2.29)$ & $0.51(0.031-8.22)$ & $0.61(0.37-1.01)$ & $0.79(0.41-1.51)$ \\
\hline
\end{tabular}

EWGSOP European Working Group on Sarcopenia in Older People, MMSE Mini-mental State Examination, n/a not applicable

Adjusted for age at baseline, smoking status, Charlson comorbidity index and total fat mass

${ }^{a}$ The results are showed as odds ratios per one standard deviation in continuous variables

${ }^{\mathrm{b}}$ Assistance with bathing, dressing and/or toileting 
Table 4 Longitudinal associations between sarcopenia at baseline and independent ageing five years later, and between their respective components

\begin{tabular}{|c|c|c|c|c|c|c|}
\hline & Independent aging & MMSE $\geq 25 p$ & No dementia & Community-dwelling & $\begin{array}{l}\text { No assistance with } \\
\text { personal care } \\
\text { b }\end{array}$ & $\begin{array}{l}\text { No assistance with } \\
\text { outdoor walking } \\
n=106\end{array}$ \\
\hline & $n=87$ & $n=85$ & & & & \\
\hline & \multicolumn{6}{|c|}{ Odds ratio ( $95 \%$ Confidence interval) } \\
\hline \multicolumn{7}{|l|}{ EWGSOP1 } \\
\hline Sarcopenia & $1.04(0.40-2.74)$ & $1.09(0.20-5.86)$ & $1.76(0.35-8.78)$ & $2.57(0.45-14.7)$ & $1.89(0.39-9.07)$ & $0.36(0.10-1.31)$ \\
\hline \multicolumn{7}{|l|}{ EWGSOP2 } \\
\hline Probable sarcopenia & $0.56(0.24-1.30)$ & $0.80(0.17-3.76)$ & $0.26(0.058-1.15)$ & $0.39(0.095-1.62)$ & $0.61(0.19-1.94)$ & $0.55(0.14-2.26)$ \\
\hline Confirmed sarcopenia & $1.14(0.43-3.06)$ & $2.19(0.25-19.2)$ & $1.79(0.36-8.82)$ & $1.74(0.35-8.74)$ & $1.22(0.31-4.75)$ & $1.18(0.23-5.93)$ \\
\hline Severe sarcopeni & $\mathrm{n} / \mathrm{a}$ & $\mathrm{n} / \mathrm{a}$ & $\mathrm{n} / \mathrm{a}$ & $\mathrm{n} / \mathrm{a}$ & $n / a$ & n/a \\
\hline Skeletal muscle index ${ }^{a}, \mathrm{~kg} / \mathrm{m}^{2}$ & $1.04(0.71-1.53)$ & $0.80(0.41-1.56)$ & $0.75(0.42-1.34)$ & $0.94(0.53-1.66)$ & $0.88(0.52-1.48)$ & $1.00(0.55-1.83)$ \\
\hline Gait speed $^{\mathrm{a}}, \mathrm{m} / \mathrm{s}$ & $1.84(1.19-2.82)$ & $1.15(0.59-2.25)$ & $1.63(0.94-2.83)$ & $1.35(0.77-2.38)$ & $2.34(1.29-4.26)$ & $1.21(0.67-2.20)$ \\
\hline Hand grip strength ${ }^{\mathrm{a}}, \mathrm{kg}$ & $1.43(0.95-2.14)$ & $0.91(0.44-1.88)$ & $1.39(0.76-2.54)$ & $1.94(1.01-3.74)$ & $1.37(0.80-2.36)$ & $1.44(0.73-2.84)$ \\
\hline Chair stand test ${ }^{\mathrm{a}}, \mathrm{s}$ & $1.01(0.66-1.54)$ & $1.35(0.43-4.20)$ & $1.09(0.58-2.03)$ & $0.88(0.55-1.40)$ & $1.04(0.57-1.88)$ & $1.10(0.51-2.35)$ \\
\hline
\end{tabular}

EWGSOP European Working Group on Sarcopenia in Older People, MMSE Mini-mental State Examination, n/a not applicable Adjusted for age at baseline, smoking status, Charlson comorbidity index and total fat mass

${ }^{a}$ The results are showed as odds ratios per one standard deviation in continuous variables

${ }^{\mathrm{b}}$ Assistance with bathing, dressing and/or toileting

participation, among others. With this heterogeneity in outcomes it is difficult to compare the results. No longitudinal study with a similar outcome was found. Previous studies on subjects with mean age $\geq 75$ years have not shown any association between SMI and dementia or severe cognitive impairment [13, 36, 46]. Furthermore, SMI was not correlated with mobility in older women [47]. However, low muscle mass at mean age 77 was associated with ADL disability and institutionalisation five to seven years later for Australian community-dwelling men [48].

Muscle strength is lost more rapidly with ageing than muscle mass [49] and this can be one reason for finding an association between muscle function, but not muscle mass, and independent ageing in ULSAM. Furthermore, not just muscle size but also changes in muscle quality, i.e. architecture and biochemistry, may require attention [49]. However, muscle quality, including the amount of myosteatosis, cannot be evaluated by DXA.

When we related the composite sarcopenia diagnoses to our outcomes we noticed that severe sarcopenia, but not confirmed or probable sarcopenia, was cross-sectionally associated with loss of independent ageing and needing assistance when outdoor walking. However, severe sarcopenia was only present in $2 \%$ of the participants. To the knowledge of the authors, only two studies using the EWGSOP2 definition have, so far, been published $[9,10]$. These studies investigated the prevalence of sarcopenia and its association with mortality and risk factors in populations with a mean age around 75 years. Sarcopenia, as defined by the EWGSOP1 definition, was not associated with independent ageing in the present study. The only similar study found was the cross-sectional study by Tolea who showed an association between sarcopenia and combined impairment in cognitive and physical performance [15]. In one cross-sectional study sarcopenia was associated with cognitive impairment [14], while no association was found in another study [13]. The participants in both studies had a mean age $>80$ years. However, one meta-analysis also including younger subjects found a correlation between sarcopenia and cognitive impairment [12]. Another meta-analysis also found an association between sarcopenia and subsequent functional decline [11]. Finally, sarcopenia at mean age 77 years was associated with ADL disability and institutionalisation five to seven years later for community-dwelling Australian men [48]. However, comparisons may be slightly hampered due to somewhat different definitions used.

The prevalence of sarcopenia differs by definition criteria but also by age and gender [50]. When using the EWGSOP1 definition the prevalence in ULSAM, as well as for men in the Newcastle $85+$ Study, was actually the same, $21 \%$ [51]. . In Italian octogenarian men the prevalence was $17 \%$ [52], while $13 \%$ of Belgian octogenarian men had sarcopenia [53]. These three studies also used the EWGSOP1 definition [5], but measured muscle mass with BIA, and not DXA. Using the updated definition on confirmed sarcopenia decreased the prevalence from 21 to $20 \%$ in the present study. In the only two published studies, so far, using the up-dated definition, the prevalence was below $10 \%$, which most likely is explained by the lower mean age in these populations $[9,10]$.

Regarding strengths and limitations, this cohort consisted of men of similar age and ethnic background, 
which limits its generalizability. On the other hand this design makes it possible to exclude age, gender and ethnicity as confounders. The study population was skewed toward a healthier population than the background population, i.e. only $5 \%$ had dementia at baseline, which is lower than expected in this age group. This further reduces the generalizability. However, this might lead to underestimation of the associations observed, rather than overestimation. Misclassification is a possibility as some of the components for independent ageing were self-reported, but this potential introduction of bias was reduced by reviewing the medical records for consistency with the self-reported information. Participants who lacked information on MMSE at follow-up might also have been wrongly classified as independently aged. Although the associations were adjusted, other possible confounders, such as depression [54], might not have been taken into consideration. Finally, it is not possible to draw any conclusions about the direction of the associations between exposure and outcome in the cross-sectional analysis. However, in the longitudinal analysis of participants with independent ageing at baseline, a high GS or HGS predicted independent ageing five years later.

GS was measured with a dynamic start giving a high mean GS compared to other studies in the same age group [55]. Also, the effect of HGS might be affected as both hands, and not only the dominant, were measured and the highest value was used. This might lead to a false and excessively low prevalence of sarcopenia but also an underestimation of the associations with sarcopenia, GS and HGS.

In conclusion, muscle function, but not muscle mass, was associated with independent ageing in very old men. When using the updated EWGSOP2 definition, severe, but not probable or confirmed sarcopenia, was associated with loss of independent ageing. Otherwise, none of the present definitions of sarcopenia according to EWGSOP were associated with independent ageing. Measuring GS, HGS and CST is easy and possible to do in the clinical setting. Those assessments may identify individuals who can benefit from interventions that might at least postpone the loss of independence. However, further studies are needed to identify these possible interventions.

\footnotetext{
Abbreviations

ADL: Activities of daily living; BIA: Bio-electrical impedance analysis; BMI: Body mass index; Cl: Confidence interval; CST: Chair stand test; DXA: Dual energy X-ray absorptiometry; EWGSOP: European Working Group on Sarcopenia in Older People; GS: Gait speed; HGS: Hand grip strength; MMSE: Mini-Mental State Examination; OR: Odds ratio; SD: Standard deviations; SMI: Skeletal muscle index; ULSAM: Uppsala Longitudinal Study of Adult Men
}

\section{Acknowledgements}

The authors thank all the participants in ULSAM; Käthe Ström, research nurse; Vilmantas Giedraitis, ULSAM data manager; and Karl Michaëlsson, responsible for the DXA. Björn Zethelius is employed at the Swedish Medical Products Agency, SE-751 03 Uppsala, Sweden. The views expressed in this paper are the personal views of the authors and not necessarily the views of the government agency.

\section{Funding}

KF was supported by grants from the Thuréus foundation. The foundation had no role in the design, conduct of research or decision of publication.

\section{Availability of data and materials}

An anonymized dataset is available to collaborative partners of the ULSAM study group after approved request. The corresponding author could be contacted for further information.

\section{Authors' contributions}

KF, BZ, TC and LK contributed to the conception and design of the study and to the acquisition of data. KF performed the statistical analyses. All contributed to the interpretation of data. KF contributed to drafting the article. BZ, TC and LK contributed to revising the article critically for important intellectual content. All authors have approved to the final version of this manuscript.

\section{Ethics approval and consent to participate}

The study was approved by the Regional Ethical Review Board at Uppsala University (Dnr 2007/338 and Dnr 2013/350), and all subjects provided written informed consent.

\section{Consent for publication}

Not applicable.

\section{Competing interests}

TC has received unconditional research grants from Nutricia, Nestlé and Fresenius-Kabi, and is giving lectures arranged by Nutricia, Nestlé, FreseniusKabi and Abbott. KF, BZ and LK have no competing interests to declare.

\section{Publisher's Note}

Springer Nature remains neutral with regard to jurisdictional claims in published maps and institutional affiliations.

\section{Author details}

${ }^{1}$ Department of Public Health and Caring Sciences/Geriatrics, Uppsala University, Box 564, 75122 Uppsala, Sweden. '2Department of Public Health and Caring Sciences/Clinical Nutrition and Metabolism, Uppsala University, Uppsala, Sweden.

Received: 31 October 2018 Accepted: 22 April 2019

Published online: 29 May 2019

References

1. Hofman CS, Makai $\mathrm{P}$, Boter $\mathrm{H}$, et al. The influence of age on health valuations: the older olds prefer functional independence while the younger olds prefer less morbidity. Clin Interv Aging. 2015;10:1131-9.

2. Franzon $K$, Zethelius $B$, Cederholm T, et al. Modifiable midlife risk factors, independent aging, and survival in older men: report on long-term followup of the Uppsala longitudinal study of adult men cohort. J Am Geriatr Soc. 2015;63(5):877-85.

3. Franzon K, Byberg L, Sjogren $P$, et al. Predictors of independent aging and survival: a 16-year follow-up report in octogenarian men. J Am Geriatr Soc. 2017;65(9):1953-60.

4. Rosenberg $\mathbb{H}$. Sarcopenia: origins and clinical relevance. J Nutr. 1997;127(5 Suppl):990S-1S.

5. Cruz-Jentoft AJ, Baeyens JP, Bauer JM, et al. Sarcopenia: European consensus on definition and diagnosis: report of the European working group on sarcopenia in older people. Age Ageing. 2010;39(4):412-23.

6. Fielding RA, Vellas B, Evans WJ, et al. Sarcopenia: an undiagnosed condition in older adults. Current consensus definition: prevalence, etiology, and consequences. International working group on sarcopenia. J Am Med Dir Assoc. 2011;12(4):249-56.

7. Studenski SA, Peters KW, Alley DE, et al. The FNIH sarcopenia project: rationale, study description, conference recommendations, and final estimates. J Gerontol A Biol Sci Med Sci. 2014;69(5):547-58. 
8. Cruz-Jentoft AJ, Bahat G, Bauer J, et al. Sarcopenia: revised European consensus on definition and diagnosis. Age Ageing. 2019;48(1):16-31.

9. Su Y, Hirayama K, Han TF, et al. Sarcopenia Prevalence and Risk Factors among Japanese Community Dwelling Older Adults Living in a SnowCovered City According to EWGSOP2. J Clin Med. 2019:8(3).

10. Locquet M, Beaudart C, Petermans J, et al. EWGSOP2 versus EWGSOP1: impact on the prevalence of sarcopenia and its major health consequences. J Am Med Dir Assoc. 2019;20(3):384-5.

11. Beaudart C, Zaaria M, Pasleau F, et al. Health outcomes of sarcopenia: a systematic review and meta-analysis. PLoS One. 2017;12(1):e0169548.

12. Chang KV, Hsu TH, Wu WT, et al. Association Between Sarcopenia and Cognitive Impairment: A Systematic Review and Meta-Analysis. J Am Med Dir Assoc. 2016;17(12):1164 e1167-15.

13. Abellan van Kan G, Cesari M, Gillette-Guyonnet S, et al. Sarcopenia and cognitive impairment in elderly women: results from the EPIDOS cohort. Age Ageing. 2013;42(2):196-202.

14. Hsu YH, Liang CK, Chou MY, et al. Association of cognitive impairment, depressive symptoms and sarcopenia among healthy older men in the veterans retirement community in southern Taiwan: a cross-sectional study. Geriatr Gerontol Int. 2014;14(Suppl 1):102-8.

15. Tolea MI, Galvin JE. Sarcopenia and impairment in cognitive and physical performance. Clin Interv Aging. 2015;10:663-71.

16. Rantanen KK, Strandberg TE, Stenholm SS, et al. Clinical and laboratory characteristics of active and healthy aging (AHA) in octogenarian men. Aging Clin Exp Res. 2015;27(5):581-7.

17. Tyrovolas S, Haro JM, Mariolis A, et al. Skeletal muscle mass and body fat in relation to successful ageing of older adults: the multi-national MEDIS study. Arch Gerontol Geriatr. 2016;66:95-101.

18. Bell $\mathrm{CL}$, Chen $\mathrm{R}$, Masaki $\mathrm{K}$, et al. Late-life factors associated with healthy aging in older men. J Am Geriatr Soc. 2014;62(5):880-8.

19. Uppsala Longitudinal Study of Adult Men. Available at http://www.pubcare. uu.se/ulsam/ Accessed 19 Mar 2019.

20. Lochen ML, Rasmussen K. The Tromso study: physical fitness, self reported physical activity, and their relationship to other coronary risk factors. J Epidemiol Community Health. 1992;46(2):103-7.

21. Aires $N$, Selmer $R$, Thelle $D$. The validity of self-reported leisure time physical activity, and its relationship to serum cholesterol, blood pressure and body mass index. A population based study of 332,182 men and women aged 40-42 years. Eur J Epidemiol. 2003;18(6):479-85.

22. Charlson $\mathrm{ME}$, Pompei $\mathrm{P}$, Ales $\mathrm{KL}$, et al. A new method of classifying prognostic comorbidity in longitudinal studies: development and validation. J Chronic Dis. 1987;40(5):373-83.

23. Quan $H$, Sundararajan $V$, Halfon $P$, et al. Coding algorithms for defining comorbidities in ICD-9-CM and ICD-10 administrative data. Med Care. 2005; 43(11):1130-9

24. Folstein MF, Folstein SE, McHugh PR. "Mini-mental state". A practical method for grading the cognitive state of patients for the clinician. J Psychiatr Res. 1975;12(3):189-98.

25. American Psychiatric Association. Diagnostic and Statistical Manual of Mental Disorders (4th ed.). Washington, DC.; 1994.

26. McKhann G, Drachman D, Folstein M, et al. Clinical diagnosis of Alzheimer's disease: report of the NINCDS-ADRDA work group under the auspices of Department of Health and Human Services Task Force on Alzheimer's disease. Neurology. 1984;34(7):939-44.

27. McKhann GM, Albert MS, Grossman M, et al. Clinical and pathological diagnosis of frontotemporal dementia: report of the work group on frontotemporal dementia and Pick's disease. Arch Neurol. 2001;58(11): 1803-9.

28. Chui HC, Victoroff Jl, Margolin D, et al. Criteria for the diagnosis of ischemic vascular dementia proposed by the state of California Alzheimer's disease diagnostic and treatment centers. Neurology. 1992;42(3 Pt 1):473-80.

29. McKeith IG. Consensus guidelines for the clinical and pathologic diagnosis of dementia with Lewy bodies (DLB): report of the consortium on DLB international workshop. J Alzheimers Dis. 2006;9(3 Suppl):417-23.

30. Woo J, Leung J, Zhang T. Successful aging and frailty: opposite sides of the same coin? J Am Med Dir Assoc. 2016;17(9):797-801.

31. Rijk JM, Roos PR, Deckx $L$, et al. Prognostic value of handgrip strength in people aged 60 years and older: a systematic review and meta-analysis. Geriatr Gerontol Int. 2016;16(1):5-20.

32. Perera S, Patel KV, Rosano C, et al. Gait speed predicts incident disability: a pooled analysis. J Gerontol A Biol Sci Med Sci. 2016;71(1):63-71.
33. Demnitz N, Esser P, Dawes $H$, et al. A systematic review and meta-analysis of cross-sectional studies examining the relationship between mobility and cognition in healthy older adults. Gait Posture. 2016;50:164-74.

34. Quan $M$, Xun $P$, Chen $C$, et al. Walking pace and the risk of cognitive decline and dementia in elderly populations: a meta-analysis of prospective cohort studies. J Gerontol A Biol Sci Med Sci. 2017;72(2):266-70.

35. Mielke MM, Roberts RO, Savica R, et al. Assessing the temporal relationship between cognition and gait: slow gait predicts cognitive decline in the Mayo Clinic study of aging. J Gerontol A Biol Sci Med Sci. 2013;68(8):929-37.

36. Papachristou E, Ramsay SE, Lennon LT, et al. The relationships between body composition characteristics and cognitive functioning in a populationbased sample of older British men. BMC Geriatr. 2015;15:172.

37. Bullain SS, Corrada MM, Shah BA, et al. Poor physical performance and dementia in the oldest old: the 90+ study. JAMA Neurol. 2013;70(1):107-13.

38. Cohen JA, Verghese J, Zwerling JL. Cognition and gait in older people. Maturitas. 2016:93:73-7.

39. Hsu CL, Liang CK, Liao MC, et al. Slow gait speed as a predictor of 1-year cognitive decline in a veterans' retirement community in southern Taiwan. Geriatr Gerontol Int. 2017;17(Suppl 1):14-9.

40. Fougere B, Daumas M, Lilamand M, et al. Association Between Frailty and Cognitive Impairment: Cross-Sectional Data From Toulouse Frailty Day Hospital. J Am Med Dir Assoc. 2017;18(11):990 e991-5.

41. Taekema DG, Gussekloo J, Maier AB, et al. Handgrip strength as a predictor of functional, psychological and social health. A prospective populationbased study among the oldest old. Age Ageing. 2010;39(3):331-7.

42. Bullain SS, Corrada MM, Perry SM, et al. Sound body sound mind? Physical performance and the risk of dementia in the oldest-old: the 90+ study. J Am Geriatr Soc. 2016;64(7):1408-15.

43. Rothman MD, Leo-Summers L, Gill TM. Prognostic significance of potential frailty criteria. J Am Geriatr Soc. 2008;56(12):2211-6.

44. Onder G, Penninx BW, Ferrucci L, et al. Measures of physical performance and risk for progressive and catastrophic disability: results from the Women's health and aging study. J Gerontol A Biol Sci Med Sci. 2005;60(1):74-9.

45. Heiland EG, Welmer AK, Wang $R$, et al. Association of mobility limitations with incident disability among older adults: a population-based study. Age Ageing. 2016;45(6):812-9.

46. Abellan van Kan G, Rolland Y, Gillette-Guyonnet S, et al. Gait speed, body composition, and dementia. The EPIDOS-Toulouse cohort. J Gerontol A Biol Sci Med Sci. 2012;67(4):425-32.

47. Rolland Y, Lauwers-Cances V, Cristini C, et al. Difficulties with physical function associated with obesity, sarcopenia, and sarcopenic-obesity in community-dwelling elderly women: the EPIDOS (EPIDemiologie de I'OSteoporose) study. Am J Clin Nutr. 2009;89(6):1895-900.

48. Hirani $V$, Blyth $F$, Naganathan $V$, et al. Sarcopenia is associated with incident disability, institutionalization, and mortality in community-dwelling older men: the Concord health and ageing in men project. J Am Med Dir Assoc. 2015;16(7):607-13.

49. Mitchell WK, Williams J, Atherton P, et al. Sarcopenia, dynapenia, and the impact of advancing age on human skeletal muscle size and strength; a quantitative review. Front Physiol. 2012;3:260.

50. Pagotto V, Silveira EA. Applicability and agreement of different diagnostic criteria for sarcopenia estimation in the elderly. Arch Gerontol Geriatr. 2014; 59(2):288-94.

51. Dodds RM, Granic A, Davies K, et al. Prevalence and incidence of sarcopenia in the very old: findings from the Newcastle $85+$ study. J Cachexia Sarcopenia Muscle. 2017;8(2):229-37.

52. Volpato $S$, Bianchi $L$, Cherubini $A$, et al. Prevalence and clinical correlates of sarcopenia in community-dwelling older people: application of the EWGSOP definition and diagnostic algorithm. J Gerontol A Biol Sci Med Sci. 2014;69(4):438-46

53. Legrand D, Vaes B, Mathei $C$, et al. The prevalence of sarcopenia in very old individuals according to the European consensus definition: insights from the BELFRAIL study. Age Ageing. 2013;42(6):727-34.

54. Chang KV, Hsu TH, Wu WT, et al. Is sarcopenia associated with depression? A systematic review and meta-analysis of observational studies. Age Ageing. 2017:46(5):738-46.

55. Bohannon RW, Williams Andrews A. Normal walking speed: a descriptive meta-analysis. Physiotherapy. 2011;97(3):182-9. 